\title{
MODELOS DE LIMITAÇÃO DA RESPONSABILIDADE PARA O EXERCÍCIO INDIVIDUAL DA EMPRESA: EIRELI VERSUS SOCIEDADE LIMITADA UNIPESSOAL
}

\section{Luciano Monti Favaro*}

RESUMO: Mundialmente são conhecidos três modelos de limitação da responsabilidade para o exercício individual da empresa. No Brasil, em 2011, regulamentou-se a empresa individual de responsabilidade limitada - EIRELI. Em 2019, outro modelo foi regulamentado, o da sociedade limitada unipessoal. Um comparativo entre esses dois modelos é essencial para se verificar qual deles melhor atende às necessidades dos pequenos e médios empreendedores os quais são reconhecidos como os verdadeiros destinatários desses institutos. Desse comparativo decorre que a EIRELI apresenta entraves que não são verificados na sociedade limitada unipessoal razão por que, muito provavelmente, a EIRELI deixará de ser a opção escolhida.

PALAVRAS-CHAVES: modelos de limitação da responsabilidade para o exercício individual da empresa; empresa individual de responsabilidade limitada - EIRELI; sociedade limitada unipessoal; afetação patrimonial; Declaração de Direitos de Liberdade Econômica.

\section{MODELS OF LIMITATION OF LIABILITY FOR THE INDIVIDUAL EXERCISE OF THE COMPANY: EIRELI VERSUS LIMITED SOLE PROPRIETORSHIP}

\begin{abstract}
Worldwide, three models of limitation of liability for the individual exercise of the company are known. In Brazil, in 2011, the individual limited liability company - EIRELI was regulated. In 2019, another model was regulation: the limited sole proprietorship. A comparison between these two models is essential to verify which one best meets the needs of small and medium entrepreneurs (SMEs) who are recognized as the real recipients of these institutes. This comparison shows that EIRELI presents obstacles that are not found in the limited sole proprietorship. As a result, EIRELI will probably longer be the option chosen by SMEs.
\end{abstract}

KEYWORDS: models of limitation of liability for the individual exercise of the company; individual limited liability company - EIRELI; limited sole proprietorship; patrimonial separation; Declaration of Economic Freedom Rights.

\section{Introdução}

Diferentemente de outros países, em especial os europeus, durante anos a doutrina brasileira relutou em admitir a sociedade unipessoal pelo motivo de entender que um dos 
requisitos específicos para a constituição de uma sociedade é a pluralidade de sócios. Admitia-se, no entanto, a seguintes exceções de sociedade unipessoal: a sociedade subsidiária integral prevista no artigo 251 da Lei das Sociedades por Ações; a empresa pública, definida no artigo $3^{\circ}$ da Lei das Estatais, nos casos em que capital social seja integral e exclusivamente detido por um ente federativo; e a sociedade unipessoal temporária pelo período de cento e oitenta dias, em razão, por exemplo, da morte de um dos sócios, conforme estabelecido no artigo 1.033, IV, do Código Civil.

No ano de 2011, por intermédio da Lei $n^{\circ}$ 12.441, inseriu-se no Código Civil a empresa individual de responsabilidade limitada - EIRELI como uma nova pessoa jurídica de direito privado. Malgrado as divergências doutrinárias acerca do modelo de limitação da responsabilidade desse instituto, não se discute o fato de se tratar de uma pessoa jurídica constituída por uma única pessoa titular da totalidade do capital social, tal qual previsão no artigo 980-A, do Código Civil.

Posteriormente, por meio da Lei $\mathrm{n}^{\circ}$ 13.247, de 2016, passou-se a admitir, no ordenamento jurídico brasileiro, a constituição de sociedade unipessoal para fins exclusivos da atividade de advocacia. Mais recentemente, em 20 de setembro de 2019, mediante a Lei ${ }^{\circ}$ 13.874, que instituiu a Declaração de Direitos de Liberdade Econômica, previu-se a possibilidade de a sociedade limitada ser constituída por uma única pessoa podendo ser utilizada para o desenvolvimento de quaisquer atividades econômicas, sejam elas de natureza simples ou empresária.

É inegável que a normatização desses institutos decorreu da necessidade de se atender aos anseios de pequenos e médios empreendedores para o desenvolvimento dessas atividades. O risco de desenvolvê-las é grande, torna-se ainda maior se o empreendedor tiver de responder ilimitadamente pelas obrigações decorrentes dessa atividade, na qualidade de um empresário individual. $\mathrm{O}$ intuito do legislador foi, assim, estabelecer modelos para a limitação da responsabilidade do exercício individual da empresa a fim de mitigar os riscos do empreendedor e evitar, também, a constituição das denominadas "sociedades limitadas de fachada" no qual um dos sócios apenas cede seu nome para compor o número mínimo de pessoas até então exigida na legislação.

Fato é que com o advento dessas legislações, o Brasil passou a adotar dois métodos distintos para essa limitação. Diante disso, indaga-se: se já havia a possibilidade de se 
constituir uma empresa individual com responsabilidade limitada, por qual razão o legislador inseriu nova previsão legal tratando da instituição de sociedade limitada unipessoal? Haveria alguma limitação na EIRELI que fora superada pelo novo instituto?

No presente artigo trabalha-se com a hipótese de que se a EIRELI possuía restrições, a previsão legal da sociedade limitada unipessoal veio no sentido de superar essas limitações o que poderá resultar, até mesmo, na obsolescência da utilização do instituto da EIRELI no Brasil.

O intuito por esse artigo é, assim, compreender as características da sociedade limitada unipessoal confrontando com as características da empresa individual de responsabilidade limitada estabelecidas no ordenamento jurídico brasileiro por meio das Leis $\mathrm{n}^{\circ} \mathrm{s} 13.874$, de 2019 e 12.441 , de 2011, respectivamente.

O desenvolvimento do trabalho se dará em dois tópicos nos quais serão desenvolvidos os objetivos específicos. No primeiro intenta-se analisar os modelos mundialmente conhecidos de limitação da responsabilidade para o exercício individual da empresa, quais sejam: sociedades unipessoais; afetação de um patrimônio; e a empresa individual de responsabilidade limitada com personalidade jurídica própria. No segundo tópico intenta-se contrastar a novel legislação que instituiu a sociedade limitada unipessoal com a legislação da EIRELI, no direito brasileiro, a fim de identificar qual desses institutos está mais alinhado aos anseios dos pequenos e médios empreendedores que, em última análise, são os reais destinatários dessas legislações.

Em resposta ao problema de pesquisa levantado e à indicada hipótese, propõe-se a metodologia de pesquisa descritiva bibliográfica. O trabalho se baseia em estudos doutrinários, pesquisa legislativas brasileiras, diretivas da Comunidade Econômica Europeia e da União Europeia e legislações de países europeus e sul-americano a fim de remontar um histórico dos modelos de limitação da responsabilidade para o exercício individual da empresa.

\section{Modelos de limitação da responsabilidade para o exercício individual da empresa}

Não raro a atividade empresarial é desempenhada por um empresário individual o qual assume, sozinho, todos os riscos do desenvolvimento dessa atividade. Esses riscos 
perpassa o patrimônio da empresa atingindo, por conseguinte, os bens particulares do empresário em decorrência do princípio da responsabilidade ilimitada.

Esse princípio constitui "o eixo de um inteiro sistema organizado no plano jurídico para prover à segurança das relações dos homens na ordem econômica” (MACHADO, 1956, p. 19). Por esse princípio, ao sujeitar os bens particulares do empresário à satisfação de suas obrigações, confere-se aos credores garantias contra o inadimplemento do devedorempresário.

Essa responsabilidade ilimitada, no entanto, acabava por inibir o desenvolvimento de atividade empresarial, "uma vez que nem todos estão dispostos a assumir riscos para obter rendimentos econômicos” (TOMAZETTE, 2020, p. 85). Para contornar essa situação, muitas pessoas optam em constituir uma sociedade limitada na qual um dos sócios possui um capital mínimo possível - geralmente $1 \%$ das quotas - enquanto o outro sócio - geralmente o sócio administrador - possui a quase totalidade das quotas. Trata-se, corriqueiramente, da "sociedade limitada de fachada". Essas sociedades existem apenas para atender à necessidade de pluralidade social; o sócio minoritário "não dá notícia dos negócios societários, nem se interessa por eles, não participa de deliberações, não recebe lucros”. Criou-se, assim, uma cultura empresarial "fundada sobre o desvirtuamento da figura da sociedade" (MAMEDE, 2019, p. 95).

Atento a essa técnica utilizada, o legislador passou a prever meios de limitação de responsabilidade a fim de "incentivar o desenvolvimento da própria economia" para que as pessoas possam aplicar seus recursos em atividades econômicas produtivas, sem, no entanto, correr riscos de perda de seu patrimônio para fazer frente às dívidas da empresa (TOMAZETTE, 2020, p. 85).

Os modelos mundialmente conhecidos para a limitação da responsabilidade do exercício individual da empresa são: sociedades unipessoais; afetação de um patrimônio; e a empresa individual de responsabilidade limitada com personalidade jurídica própria.

\subsection{Sociedades unipessoais limitadas}

Essa técnica, prevista em diversas legislações europeias, consiste na possibilidade de se constituir uma sociedade formada por um único sócio o qual possuirá a mesma limitação dos sócios das sociedades limitadas (TOMAZETTE, 2020, p. 85). 
Conquanto no ordenamento jurídico brasileiro a aceitação das sociedades unipessoais limitada somente tenha sido admitida recentemente, no direito estrangeiro essa aceitação data de alguns anos. Em 1980, na Alemanha, admitiu-se a constituição de sociedade de responsabilidade limitada instituída por uma só pessoa, natural ou jurídica, desde que fosse constituída com capital mínimo de cinquenta mil Marcos totalmente integralizado ou de vinte e cinco mil integralizado no ato da subscrição, com garantia real em relação ao restante (CAMPINHO, 2018, p. 129). Atualmente, a legislação alemã ainda continua a permitir a constituição dessas sociedades desde que o capital social seja de pelo menos vinte e cinco mil Euros (ALEMANHA, GmbH-Gesetz, $\S ~ 1$ e 5).

No ano de 1985 foi a França que, por intermédio de uma alteração legislativa (Lei n. 85.697, de 11 de julho), passou a admitir a constituição de sociedade limitada unipessoal, conforme disposto no artigo 1.832 do Código Civil (FRANÇA, Code Civil).

Em decorrência das legislações alemã e francesa, afastou-se, nesses países, a tese até então vigente - de que a instituição de uma sociedade decorreria unicamente de um contrato. Passou-se a adotar a ideia de que é irrelevante o número de pessoas, uma vez que a sociedade é constituída apenas como uma forma de organizar a empresa.

Essa nova forma de organizar a sociedade foi difundida na Europa em razão da previsão constante na décima segunda Diretiva 89/667/CEE, adotada pela então Comunidade Econômica Europeia - CEE em 21 de dezembro de 1989 (JO L 395, p. 40-42). De acordo com o artigo $2^{\circ}$ dessa Diretiva estabeleceu-se que a sociedade poderia ter um sócio único no momento da sua constituição, bem como por força da reunião de todas as partes sociais numa única pessoa.

Das justificativas para a adoção dessa Diretiva - tal qual verificado em seu Preâmbulo -, duas importam ser analisadas: a primeira decorre do fato de que havia disparidade entre as legislações dos Estados-membros da Comunidade no tocante à constituição de sociedades de responsabilidade limitada com um único sócio. Embora as legislações de Alemanha e França estavam alinhadas, Portugal, por intermédio do Decreto-Lei $\mathrm{n}^{\mathrm{o}} 248$, de 25 de agosto de 1986, havia instituído o "estabelecimento individual de responsabilidade limitada", que se diferenciava das demais legislações pelo motivo de a legislação societária portuguesa manter-se fiel a ideia da sociedade-contrato, conforme será analisado no próximo tópico. 
Em razão do Decreto-Lei português previu-se na Diretiva 89/667/CEE que um Estado-membro poderia decidir não permitir a existência de sociedades unipessoais caso sua legislação previsse a possibilidade de o empresário individual constituir uma empresa de responsabilidade limitada com um patrimônio afeto a uma determinada atividade desde que a essa empresa fossem estabelecidas garantias equivalentes às estabelecidas na Diretiva.

Outra justificativa relevante apontada no Preâmbulo é a de que para a adoção dessa Diretiva considerou-se o Programa de Ação para as pequenas e médias empresas adotado pelo Conselho das Comunidades Europeias em 3 de novembro de 1986. A Diretiva estava, assim, direcionada às pequenas e médias empresas as quais são constituídas, em regra, sob a forma societária de responsabilidade limitada podendo adotar, portanto, a forma societária unipessoal limitada. Quanto às sociedades anônimas, já havia, no âmbito da CEE, diretivas aplicáveis a elas concernentes a constituição, capital, fusões, cisões. Apesar disso, estabeleceu-se no artigo $6^{\circ}$ da Diretiva 89/667/CEE que as disposições da Diretiva eram aplicáveis nos Estados-membros que permitissem a existência de sociedades unipessoais também em relação às sociedades anônimas.

Ainda de acordo com essa Diretiva, estabeleceu-se que os Estados-membros da Comunidade teriam prazo até $1^{\circ}$ de janeiro de 1992 para cumprimento de suas disposições. Países, no entanto, que previssem em suas legislações a possibilidade de o empresário individual constituir uma empresa de responsabilidade limitada com um patrimônio afeto a uma determinada atividade estariam dispensados do cumprimento da diretiva desde, de igual modo, que a essas empresas se previsse garantias equivalentes às impostas na diretiva, bem como pelas outras disposições comunitárias, aplicáveis às sociedades unipessoal limitada.

Portugal que já se utilizava do método de estabelecimento individual de responsabilidade limitada, por meio do Decreto-Lei $n^{\circ}$ 248, de 25 de agosto de 1986, estaria, portanto, dispensado da adoção da Diretiva 89/667/CEE. Não obstante, em 1996, mediante o Decreto-Lei $\mathrm{n}^{\mathrm{o}} 257$, de 31 de dezembro, passou a adotar a sociedade unipessoal por quotas. Inseriu-se, por esse Decreto-Lei, o capítulo $\mathrm{X}$ ao título III no Código das Sociedades Comerciais. De acordo com o artigo 270-A, a "sociedade unipessoal por quotas é constituída por um sócio único, pessoa singular ou coletiva, que é o titular da totalidade do capital social”. Em Portugal passou-se, a partir de então, a vigorar os dois modelos para a limitação da responsabilidade do exercício individual da empresa. 
A Diretiva 89/667/CEE sofreu, posteriormente, diversas alterações até ser revogada pela Diretiva 2009/102/CE, de 16 de setembro de 2009 (UNIÃO EUROPEIA, JO L 258, 1.10.2009, p. 20-25), vigente até o momento, a qual manteve as disposições substanciais da primitiva diretiva. Assim, de acordo com o artigo $2^{\circ}$ da Diretiva de 2009, "a sociedade pode ter um sócio único no momento da sua constituição, bem como por força da reunião de todas as partes sociais numa única pessoa (sociedade unipessoal)”.

No direito brasileiro, durante anos a doutrina tem relutado em admitir a sociedade unipessoal por entender que um dos requisitos específicos para a constituição de uma sociedade é a pluralidade de sócios. Salvo algumas exceções, a sociedade - seja ela de responsabilidade limitada ou ilimitada - deveria ser constituída por mais de uma pessoa, mormente em decorrência do affectio societatis entendido como um dos elementos específicos para a constituição de uma sociedade.

Entre as exceções pode se citar: a) a sociedade subsidiária integral prevista no artigo 251 da Lei das Sociedades por Ações (Lei $n^{\circ}$ 6.404, de 15 de dezembro de 1976) segundo o qual “a companhia pode ser constituída, mediante escritura pública, tendo como único acionista sociedade brasileira"; b) a empresa pública, que é a "entidade dotada de personalidade jurídica de direito privado, com criação autorizada por lei e com patrimônio próprio, cujo capital social é integralmente detido pela União, pelos Estados, pelo Distrito Federal ou pelos Municípios" - nos termos do artigo $3^{\circ}$ da Lei das Estatais (Lei $n^{\circ} 13.303$, de 30 de junho de 2016) - desde que o seu capital social seja integral e exclusivamente detido por um dos referidos entes federativos; c) e a sociedade unipessoal temporária pelo período de cento e oitenta dias, em razão, por exemplo, da morte de um dos sócios, conforme estabelecido no artigo 1.033, IV, do Código Civil. Há entendimento, no entanto, que essa terceira exceção acabou por ser revogada tacitamente com a previsão legal da sociedade limitada unipessoal. Isso porque, se uma sociedade limitada passar a ter um único sócio, o sócio remanescente poderá transformá-la em uma sociedade unipessoal, com igual limitação da responsabilidade, sem implicar, necessariamente, em sua dissolução (NEGRÃO, 2020, p. 326).

Em 2011, mediante a Lei $\mathrm{n}^{\circ}$ 12.441, passou-se a admitir a empresa individual de responsabilidade limitada - EIRELI como uma nova pessoa jurídica de direito privado, tal qual previsão no artigo 980-A, do Código Civil. Já a sociedade unipessoal somente passou a ser admitida, por intermédio da Lei $\mathrm{n}^{\circ}$ 13.247, de 2016, para fins exclusivos da atividade de 
advocacia. Por essa Lei alterou-se o Estatuto da Advocacia (Lei $n^{\circ} 13.247$, de 1994) prevendo-se que "os advogados podem reunir-se em sociedade simples de prestação de serviços de advocacia ou constituir sociedade unipessoal de advocacia”. Nesse caso, no entanto, a responsabilidade do sócio único - no caso do advogado - é subsidiária e ilimitada "pelos danos causados aos clientes por ação ou omissão no exercício da advocacia, sem prejuízo da responsabilidade disciplinar em que possam incorrer."

Já a sociedade limitada unipessoal somente foi normatizada em 20 de setembro de 2019, mediante a Lei $\mathrm{n}^{\circ}$ 13.874, que instituiu a Declaração de Direitos de Liberdade Econômica. Previu-se a possibilidade de a sociedade limitada ser constituída por uma única pessoa podendo ser utilizada para o desenvolvimento de quaisquer atividades econômicas. Essa previsão normativa, malgrado não apresente as restrições da EIRELI - conforme análise a ser efetuada nesse trabalho - não foi bem aceita por parte da doutrina que entende haver "desvirtuamento das regras do direito societário para essa limitação de riscos" (TOMAZETTE, 2020, p. 85).

Alguns entendem que novo instituto inserido no ordenamento jurídico brasileiro não é realmente uma sociedade unipessoal - apesar do nomen juris -, mas sim uma nova pessoa jurídica, tal qual a EIRELI. Para esses, a sociedade limitada unipessoal prevista no artigo $1.052, \S 1^{\circ}$, do Código Civil, seria mera variação da EIRELI. Critica o fato de que o legislador, apesar de ter tomado o cuidado de respeitar o princípio da unidade patrimonial, trouxe uma redação tecnicamente sofrível ao dispositivo "dando a entender a criação de uma sociedade unipessoal, o que não se mostra compatível com o conceito de sociedade que o próprio legislador civil concebeu no art. 981” (NEGRÃO, 2020, p. 325-326).

O fato é que o legislador, ao regulamentar a sociedade limitada unipessoal, acabou por não alterar o artigo 981 do Código Civil - talvez por uma omissão do legislador - o que pode levar o entendimento de que a sociedade somente é aquela constituída por pessoas que celebram contrato de sociedade. Por esse entendimento, quisesse o legislador estabelecer realmente uma sociedade limitada unipessoal, afastando-se da ideia de sociedade-contrato, deveria ter alterado o artigo 981.

Conquanto às críticas, deve-se, no entanto, reconhecer que o intuito do legislador, ao estabelecer a sociedade limitada unipessoal, foi buscar adequar a legislação brasileira aos anseios dos empreendedores, já que a EIRELI apresenta diversas restrições legais. 


\subsection{Afetação de um patrimônio}

A criação de um patrimônio de afetação é outro método adotado para a limitação de riscos no exercício individual de uma atividade empresarial. Trata-se da possibilidade de se separar "parte do patrimônio do titular para vinculá-lo ao exercício da atividade" (TOMAZETTE, 2020, p. 85). Essa técnica "se produz como complemento necessário e indeclinável de uma separação patrimonial, onde ficam circunscritos os bens responsáveis de tal modo que, patrimônio separado e responsabilidade limitada (...) se conjugam numa unidade permanente e indissolúvel” (MACHADO, 1956, p. 272).

Esse método foi utilizado, por exemplo, no referido Decreto-Lei $\mathrm{n}^{\circ} 248$, de 25 de agosto de 1986, de Portugal, por meio do qual se instituiu o estabelecimento mercantil individual de responsabilidade limitada - E.I.R.L. A motivação para a essa previsão legislativa era limitar a "responsabilidade do comerciante em nome individual pelas dívidas contraídas na exploração de sua empresa". No entanto, diferentemente de Alemanha e França - que em anos anteriores haviam adotado em suas legislações a sociedade limitada unipessoal -, Portugal manteve-se fiel à ideia de sociedade-contrato não permitindo, naquele momento, a constituição de sociedade unipessoal em sua legislação.

Das exposições de motivo do referido Decreto-Lei vislumbra-se que, à época, havia debates se à E.I.R.L. deveria ser atribuída uma personalidade jurídica ou um patrimônio separado ou autônomo, visto como um patrimônio de afetação. A segunda opção foi a escolhida pelo legislador português, conforme se extrai do artigo $1^{\circ}, 2$, do Decreto-Lei $\mathrm{n}^{\circ} 248$ "o interessado afetará ao estabelecimento individual de responsabilidade limitada uma parte do seu patrimônio, cujo valor representará o capital inicial do estabelecimento”.

De acordo com o professor Dr. Coutinho de Abreu (2002, p. 238), o E.I.R.L. é "um patrimônio autônomo ou separado (do restante do patrimônio do comerciante individual): em regra, os bens afetados ao estabelecimento respondem apenas pelas dívidas contraídas no desenvolvimento das atividades de que ele é instrumento. Por outro lado, por essas dívidas respondem somente aqueles bens".

Em 22 de maio de 2019, mediante a Lei $\mathrm{n}^{\circ}$ 2019-486, o direito francês passou a admitir o método de afetação do patrimônio ao inserir no Código Comercial regras para a instituição do empresário individual de responsabilidade limitada. De acordo com o artigo 526-6 do Código Comercial francês, para o exercício de atividade como empresário individual 
com responsabilidade limitada, "o empresário individual atribui à sua atividade profissional um patrimônio separado de seu patrimônio pessoal, sem a criação de uma pessoa coletiva, nas condições previstas no artigo L. 526-7”.

As críticas sobre esse método residem no fato de que o patrimônio, por ser uma universalidade, não admitiria uma afetação específica. Quando da exposição de motivos do Decreto-Lei $\mathrm{n}^{\circ} 248$, de 1986, de Portugal, rememorou-se alguns doutrinadores mais antigos Aubry e Rau, por exemplo - que não admitiam a possibilidade de divisibilidade do patrimônio. Ao longo dos anos, no entanto, vem se admitindo, em determinados casos, a segregação patrimonial, tal qual admitida por Portugal nesse Decreto-Lei.

No direito brasileiro verifica-se alguns exemplos de segregação do patrimônio, como é o caso nas incorporações imobiliárias previsto no artigo 31-A da Lei $\mathrm{n}^{\circ} 4.591$, de 16 de dezembro de 1964. De acordo com esse dispositivo permitiu-se que, a critério do incorporador, a “incorporação poderá ser submetida ao regime da afetação, pelo qual o terreno e as acessões objeto de incorporação imobiliária, bem como os demais bens e direitos a ela vinculados, manter-se-ão apartados do patrimônio do incorporador e constituirão patrimônio de afetação, destinado à consecução da incorporação correspondente e à entrega das unidades imobiliárias aos respectivos adquirentes".

Embora a lei seja de 1964, esse dispositivo foi inserido pela Lei $\mathrm{n}^{\circ} 10.931$, de 2 de agosto de 2004, em decorrência de um famoso caso de falência de uma incorporadora brasileira - caso Encol. Para resgatar a confiança do consumidor no mercado de incorporação, o legislador brasileiro optou por permitir a afetação patrimonial no caso de incorporação imobiliária. Esse regime de afetação é, inclusive, muito utilizado na atualidade pelas incorporadoras imobiliárias brasileiras concedendo, assim, maior segurança patrimonial aos consumidores que adquirem, por exemplo, imóveis na planta.

Há, ainda, outros exemplos no ordenamento jurídico brasileiro de afetação do patrimônio como é o caso do patrimônio do empresário individual incapaz que continua a empresa antes exercida por ele enquanto capaz, por seus pais ou pelo autor de herança. Não ficarão sujeitos ao resultado da empresa, os bens que o incapaz já possuía, ao tempo da sucessão ou da interdição, desde que estranhos ao acervo daquela, nos termos do artigo 974, § $2^{\circ}$, do Código Civil.

O patrimônio de afetação das câmaras e prestadoras de serviços de compensação e liquidação financeira que integram o sistema de pagamento é outro exemplo. Nos termos do 
artigo $5^{\circ}$ da Lei $n^{\circ} 10.214$, de 2001, “as câmaras e os prestadores de serviços de compensação e de liquidação responsáveis por um ou mais ambientes sistemicamente importantes deverão, obedecida a regulamentação baixada pelo Banco Central do Brasil, separar patrimônio especial, formado por bens e direitos necessários a garantir exclusivamente o cumprimento das obrigações existentes em cada um dos sistemas que estiverem operando".

Percebe-se, assim, não ser desconhecido no ordenamento jurídico a possibilidade de afetar um patrimônio desde que para uma finalidade específica. No caso do Brasil, no entanto, a afetação do patrimônio ficou restrita a essas hipóteses não havendo a possibilidade de afetálo para o exercício da empresa.

Alguns doutrinadores registram que essa é a melhor técnica para a limitação da responsabilidade daquele que intenta desenvolver uma atividade empresarial, pois dispensa a constituição de uma nova pessoa jurídica - tal qual se verificará no caso da empresa individual de responsabilidade limitada - tampouco é necessário a instituição de uma sociedade limitada unipessoal o qual, conforme verifiado, poderia desvirtuar as regras do direito societário (MACHADO; BRUSCATO; TOMAZETTE).

\subsection{Empresa individual de responsabilidade limitada com personalidade jurídica própria}

O terceiro método admitido como meio de limitação da responsabilidade do exercício individual da empresa é a constituição de uma nova pessoa jurídica. Trata-se de uma espécie de personificação da empresa. Atribui-se, assim, "personalidade jurídica à empresa individual, a fim de congregar, em torno do sujeito de direito, diverso da pessoa do empresário, as relações jurídicas emergentes da atividade empreendedora (MACHADO, 1956, p. 276).

Há críticas quanto a utilização desse método, uma vez que "não é a personalização da sociedade que limita a responsabilidade, mas a existência de regra específica de limitação de responsabilidade, tanto que nem toda pessoa jurídica está associada a uma responsabilidade" (MACHADO, 1956, p. 279; TOMAZETTE, 2020, p. 87). De todo modo, essa técnica é utilizada tendo sido essa a opção de alguns legisladores a exemplo do Chile e do Brasil.

No caso do Chile, em 2003, por intermédio da Lei $\mathrm{n}^{\mathbf{0}}$ 19.857, de 24 de janeiro, instituiu-se a empresa individual de responsabilidade limitada. Os destinatários naturais dessa 
empresa foram os pequenos empresários. $\mathrm{O}$ intuito legislativo foi evitar que as pessoas com espírito empresarial recorressem a constituição de sociedades de fato - também chamados de sociedades com testa de ferro (MARTINIC, 2005, p. 36). De acordo com os artigos $1^{\mathrm{o}}$ e $2^{\circ}$ da Lei chilena, autorizou-se que toda pessoa natural pudesse estabelecer empresa individual de responsabilidade limitada entendida como a pessoa jurídica que possui patrimônio distinto do seu titular.

No caso do Brasil, a regulamentação se deu pela Lei $n^{\circ} 12.441$, de 2011, que inseriu o artigo 980-A no Código Civil instituindo a empresa individual de responsabilidade limitada - EIRELI que é aquela constituída por uma única pessoa titular da totalidade do capital social, devidamente integralizado, que não será inferior a 100 (cem) vezes o maior salário-mínimo vigente no País".

Ressalta-se que alguns doutrinadores entendem que o sistema adotado pelo Brasil ao instituir a EIRELI foi o da afetação do patrimônio, já que há uma separação do patrimônio da pessoa física (VERÇOSA, 2011, p. 269). Outros entendem que o método é o da sociedade unipessoal (MAMEDE, 2019, p. 95; COELHO, 2012, p. 409). Campinho (2018, p. 251) afirma que a EIRELI é uma modalidade de sociedade limitada "com o traço característico, que lhe imprime particularidade, de ser formada por um único sócio”. Essa interpretação decorre do fato que o legislador, quando do trâmite do projeto de lei de criação da EIRELI, ter disposto que a instituição dessa modalidade estaria ao encontro da legislação de diversos países europeus e das Américas, que consagram o modelo jurídico da sociedade unipessoal. Sociedade essa "integrada por pessoa natural que estaria possibilitada, pois, de limitar a sua responsabilidade no exercício da atividade econômica, não mais precisando para isso ter que se unir a outro sócio para compor uma pluralidade social” (CAMPINHO, 2018, p. 252).

Não obstante essa justificação, a opção do legislador pela constituição de uma nova pessoa jurídica é evidenciada pela inserção de um inciso no artigo 44 do Código Civil que se deu por meio de um substitutivo. Ao se enumerar, nesse dispositivo, as pessoas jurídicas de direito privado, o legislador inseriu o inciso VI prevendo que entre essas pessoas jurídicas inserem-se as empresas individuais de responsabilidade limitada. Dessa feita, rechaçada são as teses de que se trata de uma sociedade unipessoal. Tampouco se pode afirmar que o método adotado no caso da EIRELI é o da afetação patrimonial já que "nenhum dos dispositivos introduzidos faz referência à segregação patrimonial”. "Em suma, a EIRELI no Brasil é uma 
pessoa jurídica criada como centro autônomo de direitos e obrigações para o exercício individual da atividade empresarial" (TOMAZETTE, 2020, p. 88-89).

Trata-se, assim, de um sistema de personificação da empresa, conforme reconhecido por meio dos Enunciados nº 3 e 469 emitidos por ocasião das I e V Jornadas de Direito Civil, respectivamente, realizadas pelo Conselho de Justiça Federal - CJF, a saber:

Enunciado 3, I Jornada de Direito Civil, CJF: A Empresa Individual de Responsabilidade Limitada - EIRELI não é sociedade unipessoal, mas um novo ente, distinto da pessoa do empresário e da sociedade empresária.

Enunciado 469, V Jornada de Direito Civil, CJF: A empresa individual de responsabilidade limitada (EIRELI) não é sociedade, mas novo ente jurídico personificado.

Até mesmo pela estrutura legislativa optada pelo legislador é possível extrair que a EIRELI é uma nova pessoa jurídica. Fosse uma sociedade unipessoal com responsabilidade limitada, teria inserido os novos dispositivos que a regulamentaram junto com o capítulo referente às sociedades limitada - tal qual se deu com o novel instituto da sociedade limitada unipessoal. Pelo contrário, o legislador optou por instituir um novo Título destinado à regulamentação dela, em que pese constar desse título um único dispositivo com alguns parágrafos. De todo modo, no que couber, previu-se que as regras aplicáveis às sociedades limitadas podem ser aplicadas à EIRELI, nos termos do artigo 980-A, $\S 6^{\circ}$ do Código Civil.

$\mathrm{Na}$ citada Lei chilena, diferentemente, optou-se em regulamentar a empresa individual de responsabilidade limitada sob vários aspectos como é o caso do modo de/da: sua constituição, que se dará por escritura pública; alteração da constituição; administração da empresa; dissolução; e, até mesmo, a possibilidade de o titular responder ilimitadamente pelos seus bens em clara adoção da teoria do disregard of legal entity. Além disso, previu-se no artigo 18 que, se necessário, se aplicarão à empresa as disposições legais e tributárias aplicáveis às sociedades comerciais de responsabilidade limitada.

\section{Diferenças entre a empresa individual de responsabilidade limitada e a sociedade limitada unipessoal no direito brasileiro}

Analisados os modelos mundialmente conhecidos para a limitação da responsabilidade do exercício individual da empresa, cabe o estudo sobre as eventuais 
diferenças entre os dois institutos da legislação brasileira: EIRELI e a sociedade limitada unipessoal.

Não obstante as divergências doutrinárias acerca dos modelos que foram adotados pelo legislador brasileiro para a regulamentação da EIRELI e da sociedade limitada unipessoal, reconhece-se que no tocante à responsabilidade patrimonial não se verifica distinção uma vez que em ambas a responsabilidade será limitada. A utilização de qualquer uma delas, em última análise, atenderá o intuito do empreendedor que é ter a sua responsabilidade - advinda do desenvolvimento da atividade empresarial - limitada não se estendendo, assim, aos seus bens particulares e evitando, por conseguinte, a necessidade de se admitir sócio para a constituição de uma sociedade unicamente para fazer frente a essa responsabilidade limitada.

As diferenças residem nos aspectos de constituição. De acordo com o artigo 980-A, caput, do Código Civil, a EIRELI "será constituída por uma única pessoa titular da totalidade do capital social, devidamente integralizado, que não será inferior a 100 (cem) vezes o maior salário-mínimo vigente no País". Exige-se, assim, um capital mínimo devidamente integralizado.

Por outro lado, a sociedade limitada unipessoal não exige capital mínimo para sua constituição. Assim, consoante previsão constante no Código Civil, menciona-se, unicamente, que a sociedade limitada pode ser constituída por 1 (uma) ou mais pessoas. A não previsão de capital social mínimo para a constituição dessa sociedade decorre do princípio da livre constituição de pessoas jurídicas, que é a regra no ordenamento jurídico brasileiro. Salvo raras exceções - a exemplo de instituições financeiras, que possuem regulamentação específica do Conselho Monetário Nacional (Resolução/BACEN 2.099/1994) - não se exige que uma sociedade ou uma companhia possua capital social mínimo para constituição.

Na prática, essa diferença representará uma utilização maior da sociedade limitada unipessoal ao invés da EIRELI. Se o intuito da instituição da EIRELI foi atender pequenos e médios empreendimentos (TOMAZETTE, 2020, p. 89), a previsão de um capital social inicial com valor tão alto - que deve, reitera-se, estar integralizado na totalidade quando da constituição - acabará não sendo a opção que esse empreendedor irá escolher. Optará, muito provavelmente, pela constituição de uma sociedade unipessoal que não lhe exigirá valor mínimo de capital social. 
Importante observar que, malgrado a determinação legislativa, na prática, não se exige a comprovação do capital mínimo integralizado na EIRELI - quer no momento de sua constituição, quer a posteriori. Difere, por exemplo, da constituição de uma sociedade anônima na qual a própria Junta Comercial, Industrial e Serviços - JUCIS, exige a comprovação da realização de 10\%, como entrada, no mínimo, do preço de emissão das ações subscritas em dinheiro depositado em instituição financeira (art. 80, II, Lei das Sociedades Anônimas - LSA).

De todo modo, a exigência legal do vultoso capital mínimo para a constituição, muito provavelmente, afastará a escolha pela EIRELI já que o empreendedor - ainda mais em se tratando de pequenos empreendedores - terá a opção por um modelo que não lhe exige capital mínimo e lhe dará, de igual modo, responsabilidade limitada sobre o desenvolvimento da atividade empresarial.

Outra diferença identificada é que a pessoa natural que intentar constituir uma EIRELI somente poderá figurar em uma única empresa dessa modalidade consoante disposto no artigo 980-A, $\S 2^{\circ}$, do Código Civil. Diferentemente é a sociedade limitada unipessoal que não possui esse limitador podendo a pessoa natural constituir quantas sociedades entender necessário para o desenvolvimento de suas atividades econômicas.

A sociedade limitada unipessoal instituída, para qualquer atividade simples ou empresária, por meio da Declaração da Liberdade Econômica, está, assim, mais alinhada aos princípios da liberdade econômica e da livre iniciativa previstos no artigo $170 \mathrm{CF} / 88$. A restrição de limitar a constituição de apenas uma EIRELI por pessoa natural, prevista no art. 980-A, $\S 2^{\circ}$, sofre críticas da doutrina, uma vez que é uma regra fácil de ser burlada. Isso porque o legislador não proibiu, tampouco limitou, que a pessoa jurídica possa constituir quantas EIRELI pretender. Trata-se de uma regra proibitiva imposta unicamente à pessoa natural.

Quando da entrada em vigor da legislação, havia certa discussão sobre a possibilidade de se uma pessoa jurídica instituir uma empresa individual de responsabilidade limitada. Tanto que na V Jornada de Direito Civil do Conselho de Justiça Federal chegou-se a afirmar, por meio do Enunciado 468, que ela somente poderia ser constituída por pessoa natural. Esse entendimento, no entanto, foi superado mormente em decorrência do disposto no Anexo V da Instrução Normativa $n^{\circ}$ 38/2017 do Departamento Nacional de Registro Empresarial e Integração - DREI segundo o qual: “a Empresa Individual de Responsabilidade 
Limitada poderá ser constituída tanto por pessoa natural quanto por pessoa jurídica, nacional ou estrangeira".

Se não há limitação para que a pessoa jurídica constitua EIRELI poderia, por exemplo, uma pessoa natural valer-se de instituição de uma pessoa jurídica para, posteriormente, essa pessoa jurídica EIRELI instituir tantas quantas a pessoa natural, que a constituiu, julgasse necessária. Exemplificando, Campinho (2018, p. 254) propõe: “João forma com um sócio de fachada uma sociedade para que essa possa instituir um número ilimitado de EIRELIs, driblando a vedação que recai sobre a sua pessoa”. A restrição imposta para a constituição de uma única empresa individual de responsabilidade limitada por pessoa natural traduz-se, assim, em uma “discriminação irrazoável” Campinho (2018, p. 254).

Essas duas diferenças (capital social mínimo e limitação para a constituição) pesarão em desfavor da constituição da EIRELI. Ainda antes da edição da Lei da Liberdade Econômica, Campinho (2018, p. 133) ponderava que seria melhor evoluir para "fazer constar das regras pertinentes à sociedade limitada que ela pode ser formada por um ou mais sócios, pessoas naturais ou jurídicas". Isso acabaria, de acordo com o doutrinador, por dispensar "a figura da EIRELI, pondo, inclusive, fim a questões polêmicas que pairam sobre ela”.

O legislador brasileiro, no entanto, optou por manter as duas possibilidades estudadas podendo-se concluir que com o advento da sociedade limitada unipessoal, pela Lei da Liberdade Econômica, a EIRELI se mostrará, na prática, obsoleta (NEGRÃO, 2020, p. 272). Sendo esses institutos normatizados, em regra, para atender às necessidades dos pequenos e médios empreendedores, não se justifica limitações sob pena de se desvirtuar a finalidade para os quais os institutos foram criados. Exigir - para esses empreendedores - que o capital mínimo seja de cem vezes o maior salário mínimo soa um despropósito.

A justificativa para que se estabelecer um capital social mínimo na EIRELI é que este traria uma garantia aos credores do quanto teria a sua disposição para satisfação das obrigações (TOMAZETTE, 2020, p. 93). Fosse realmente necessário um capital mínimo tão vultoso, exigir-se-ia também das sociedades limitadas. Pelo contrário, para essas sociedades vige, quanto ao capital social, o referido princípio da livre constituição de pessoas jurídicas.

Ademais, cabe ao credor, antes de contratar com EIRELI ou sociedade, verificar as condições de garantia as quais, por óbvio, não recairão unicamente sobre a análise do valor do capital social e se esse está ou não devidamente integralizado - quiçá talvez o credor avalie o capital social. Sendo essa uma das análises para se entabular negócios, o empreendedor, caso 
se faça necessário, poderá aumentar e integralizar o capital social, razão pela qual a função de garantia, no início da atividade empresarial, é desarrazoada.

Acertada, portanto, a novel legislação que não estabeleceu capital mínimo para a constituição da sociedade limitada unipessoal, tampouco estabeleceu restrição para que apenas uma sociedade desse tipo, por pessoa natural, seja constituída razão por que essa será, na prática, muito provavelmente, a opção preferencial a ser utilizada.

\section{Considerações finais}

Diferentemente de outros países, o Brasil apenas recentemente passou a admitir modelos para a limitação da responsabilidade do exercício individual da empresa. Enquanto em países europeus esses modelos começaram a ser implementado na década de 1990, e nos países da América do Sul - como é o caso do Chile -, na década de 2000, somente na década de 2010 é que o legislador brasileiro atendeu os anseios dos pequenos e médios empreendedores quanto à limitação de sua responsabilidade no desenvolvimento de uma atividade econômica.

Em um primeiro momento, no ano de 2011, instituiu-se a empresa individual de responsabilidade limitada que, apesar de ser um avanço, trouxe regras que podem representar barreiras a esses empreendedores levando-os a continuar com a prática comum de constituição das denominadas "sociedades limitadas de fachada". Em 2016, o legislador regulamentou a sociedade unipessoal de advocacia que, no entanto, não possui responsabilidade limitada. Mais recentemente, em 2019, por meio da Declaração de Direitos de Liberdade Econômica, normatizou-se a sociedade limitada unipessoal que pode ser utilizada para o desenvolvimento de qualquer atividade econômica - simples ou empresária -, de qualquer porte - pequeno, médio ou grande.

Conquanto haja divergência doutrinária, forçoso reconhecer que com o advento dessas regulamentações, o Brasil passou a adotar dois métodos distintos para a limitação da atividade econômica individual: a empresa individual de responsabilidade limitada, que se trata de uma nova pessoa jurídica; e a sociedade limitada unipessoal.

Em síntese, esses dois modelos apresentam duas diferenças: uma no tocante ao capital social mínimo exigido para a constituição; e a limitação da constituição por pessoa natural. Concernente ao primeiro aspecto, a regulamentação da sociedade limitada unipessoal não estabeleceu capital social mínimo, enquanto para a constituição da EIRELI exige-se o 
capital de cem salários mínimos devidamente integralizados. Quanto à segunda diferença, a EIRELI traz limitação para constituição por pessoa natural que poderá figurar em uma única empresa dessa modalidade. Já a sociedade limitada unipessoal não traz essa limitação.

Essas duas diferenças desfavorecerão a utilização da EIRELI. Se o intuito, por esses institutos, é atender, na maior parte, os pequenos e médios empresários - que, inclusive, são a maioria dos empreendimentos no Brasil - dificilmente se optará pela EIRELI, em razão do elevado capital social mínimo exigido. Se a justificativa de tão elevado capital é para garantir e satisfazer o crédito dos credores - como para a obtenção de um empréstimo ou financiamento bancário, por exemplo -, pode-se, de igual modo, utilizar a sociedade limitada unipessoal estabelecendo um capital no mesmo patamar da EIRELI, mas, por outro lado, ficará livre para constituir quantas sociedades unipessoais o empreendedor, pessoa natural, julgar necessário.

As limitações da EIRELI foram, assim, superadas pela normatização da sociedade limitada unipessoal de modo que sua utilização restará obsoleta. Pode-se, por outro lado, verificar novos problemas com a utilização do novel instituto como é o caso, por exemplo, de sociedades dessa natureza com capital extremamente baixo não trazendo, assim, garantias adequadas aos credores.

Deve-se reconhecer, no entanto, que o não estabelecimento de um capital social mínimo - ainda mais em se tratando de institutos voltados para o atendimento de empreendedores de pequeno porte - é mais adequado e alinhado aos princípios constitucionais da liberdade econômica e da livre iniciativa. Além disso, vigora no ordenamento jurídico brasileiro a teoria da desconsideração da personalidade jurídica que pode ser aplicada a essas sociedades no caso de abuso da personalidade jurídica, caracterizado pelo desvio de finalidade ou pela confusão patrimonial. Trata-se de um método que resguarda os interesses dos credores em face de eventuais abusos praticado pelos sócios.

Poderia o legislador, ao invés de estabelecer um novo modelo de limitação da atividade individual, ter adequado os dispositivos da EIRELI que normatizam as limitações apontadas. Isso, inclusive, dispensaria as discussões se a sociedade limitada unipessoal é um novo modelo ou se deriva da empresa individual de responsabilidade limitada. Ao manter os dois institutos, o legislador acabou por tornar a EIRELI uma modalidade de limitação de responsabilidade que muito dificilmente continuará a ser utilizada pelos empreendedores. A 
escolha, provavelmente, será pela sociedade limitada unipessoal, já que pode ser utilizada, repisa-se para o desenvolvimento de quaisquer atividades e de qualquer porte.

\section{Referências}

ABREU, Jorge Manuel Coutinho de. Curso de direito comercial: introdução, actos de comércio, comerciantes, empresas, sinais distintivos. 4. ed., v. I, Coimbra: Almedina, 2002.

ABREU, Jorge Manuel Coutinho de. Curso de direito comercial: das sociedades. 4. ed., v. II. Coimbra: Almedina, 2013.

ALEMANHA. Gesetz betreffend die Gesellschaften mit beschränkter Haftung - GmbHGesetz. Disponível em: 〈https://www.gesetze-im-internet.de/gmbhg/>. Acesso em 10 abril 2020.

BRASIL. Constituição (1988). Constituição da República Federativa do Brasil. Brasília, DF: Assembleia Nacional Constituinte, 5 out. 1988.

BRASIL. Lei $\mathrm{n}^{\circ}$ 4.591, de 16 de dezembro de 1964. Dispõe sobre o condomínio em edificações e as incorporações imobiliárias. Brasília, DF, dez 1964.

BRASIL. Lei $\mathrm{n}^{\circ}$ 6.404, de 15 de dezembro de 1976. Dispõe sobre as Sociedades por Ações. Brasília, DF, dez 1976.

BRASIL. Lei no 10.214, de 27 de março de 2001. Dispõe sobre a atuação das câmaras e dos prestadores de serviços de compensação e de liquidação, no âmbito do sistema de pagamentos brasileiro, e dá outras providências. Brasília, DF, mar 2001.

BRASIL. Lei $\mathrm{n}^{\circ}$ 10.406, de 10 de janeiro de 2002. Institui o Código Civil. Brasília, DF, jan 2002.

BRASIL. Lei $\mathrm{n}^{\circ}$ 10.931, de 2 de agosto de 2004. Dispõe sobre o patrimônio de afetação de incorporações imobiliárias, Letra de Crédito Imobiliário, Cédula de Crédito Imobiliário, 
Cédula de Crédito Bancário, altera o Decreto-Lei $n^{\circ}$ 911, de $1^{o}$ de outubro de 1969, as Leis $n^{\circ}$ 4.591, de 16 de dezembro de 1964, $n^{\circ} 4.728$, de 14 de julho de 1965, e $n^{\circ} 10.406$, de 10 de janeiro de 2002, e dá outras providências. Brasília, DF, ago 2004.

BRASIL. Lei $\mathrm{n}^{\circ} 12.441$, de 11 de julho de 2011. Altera a Lei $n^{\circ} 10.406$, de 10 de janeiro de 2002 (Código Civil), para permitir a constituição de empresa individual de responsabilidade limitada. Brasília, DF, jul 2011.

BRASIL. Lei $n^{\circ}$ 13.247, de 12 de janeiro de 2016. Altera a Lei $n^{\circ} 8.906$, de 4 de julho de 1994 - Estatuto da Advocacia. Brasília, DF, jan 2016.

BRASIL. Lei $\mathrm{n}^{\circ}$ 13.303, de 30 de junho de 2016. Dispõe sobre o estatuto jurídico da empresa pública, da sociedade de economia mista e de suas subsidiárias, no âmbito da União, dos Estados, do Distrito Federal e dos Municípios. Brasília, DF, jun 2016.

BRASIL. Lei no 13.874, de 20 de setembro de 2019. Institui a Declaração de Direitos de Liberdade Econômica. Brasília, DF, set 2019.

BRASIL. Banco Central do Brasil. Resolução no 2.099, de 17 de agosto de 1994.

BRASIL. Departamento Nacional de Registro Empresarial e Integração. Instrução

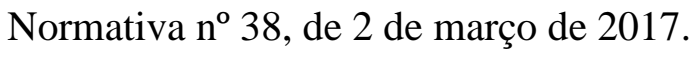

BRASIL. Conselho de Justiça Federal. I e V Jornadas de Direito Civil.

BRUSCATO, Wilges Ariana. Empresário individual de responsabilidade limitada: de acordo com o novo código civil. São Paulo: Quartier Latin, 2005.

CAMPINHO, Sergio. Curso de direito comercial: direito de empresa. 15. ed. São Paulo: Saraiva Educação, 2018. 
CHILE. Ley 19857. Autoriza el establecimiento de empresas individuales de responsabilidad limitada. Publicación 11-02-2003. Promulgación 24-01-2003.

COELHO, Fábio Ulhoa. Curso de direito comercial. 16. ed, v.2., São Paulo: Saraiva, 2012.

COMUNIDADE ECONÔMICA EUROPEIA. Décima segunda Diretiva 89/667/CEE do Conselho das Comunidades Europeias, de 21 de dezembro de 1989, em matéria de direito das sociedades relativa às sociedades de responsabilidade limitada com um único sócio. $\mathrm{JO} \mathrm{L}$ 395 de 30.12.1989, p. 40-42.

FRANÇA. Code Civil. Disponível em:

<https://www.legifrance.gouv.fr/affichCode.do;jsessionid=F511EC0864CB4615B74CED706 FCE345A.tplgfr21s_3?idSectionTA=LEGISCTA000006136390\&cidTexte=LEGITEXT0000 06070721\&dateTexte $=20200428>$ Acesso em 10 abril 2020.

FRANÇA. LOI $n^{\circ}$ 2019-486 du 22 mai 2019 relative à la croissance et la transformation des entreprises. JORF $n^{\circ} 0119$ du 23 mai 2019.

NEGRÃO, Ricardo. Curso de direito comercial e empresa: teoria geral da empresa e direito societário. 16. ed. São Paulo: Saraiva Educação, 2020.

PORTUGAL. Decreto-Lei $\mathrm{n}^{\circ}$ 248/86. Cria o estabelecimento mercantil individual de

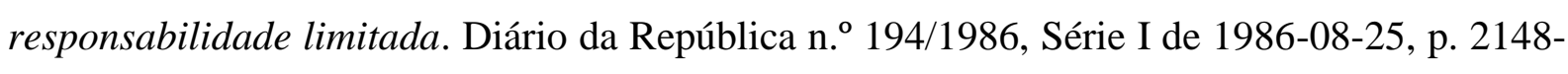
2156.

PORTUGAL. Decreto-Lei $\mathrm{n}^{\circ}$ 262/86. Código das Sociedades Comerciais. Diário da República n. ${ }^{\circ}$ 201/1986, Série I de 1986-09-02.

PORTUGAL. Decreto-Lei no 257/96. Altera o Decreto-Lei n. ${ }^{\circ}$ 262/86, de 2 de Setembro, que aprova o Código das Sociedades Comerciais, na redacção que lhe foi dada pelo Decreto-Lei n. 328/95, de 9 de Dezembro, o Código Comercial [...]. Diário da República n. o 302/1996, Série I-A de 1996-12-31, p. 4702-4711 
TOMAZETTE, Marlon. Curso de direito empresarial: teoria geral e direito societário. 11. ed. São Paulo: Saraiva Educação, 2020.

MACHADO, Sylvio Marcondes. Limitação da responsabilidade do comerciante individual. São Paulo: Max Limonad, 1956.

MAMEDE, Gladston. Direito empresarial brasileiro: empresa e atuação empresarial. 11. ed. São Paulo: Atlas, 2019.

MARTINIC, Pedro A. Trancoso. La sociedad unipersonal en Chile después de la Ley Número 19.857. Universidad de Ciencias Empresariales y Sociales. Revista Jurídica, 2005, 9, p. 24-43. Disponível em: <http://dspace.uces.edu.ar:8180/xmlui/handle/123456789/180>.

UNIÃO EUROPEIA. Diretiva 2009/102/CE do Parlamento Europeu e do Conselho de 16 de setembro de 2009 em matéria de direito das sociedades relativa às sociedades de responsabilidade limitada com um único sócio. JO L 258 de 1.10.2009, p. 20-25.

VERÇOSA, Haroldo Malheiros Duclerc. Curso de direito comercial. 3. ed., v.1. São Paulo: Malheiros, 2011. 